\title{
INTERVENCIÓN DEL ESTADO, PROPIEDAD Y CONTROL EN LAS EMPRESAS GESTORAS DEL MONOPOLIO DE TABACOS DE ESPANAA, 1887-1998
}

\author{
EUGENIO TORRES VILLANUEVA \\ Universidad Complutense
}

\section{RESUMEN}

A diferencia de los dos grandes monopolios europeos de tabacos $\longrightarrow$ f francés y el italiano-, que fueron gestionados casi siempre por el Estado, en España la gestión de este monopolio ha sido arrendada durante más de un siglo a dos empresas muy relacionadas entre sí: la Compañía Arrendataria de Tabacos (1887-1945) y Tabacalera (1945-1998). Este trabajo trata de explicar la permanencia de esta gestión arrendada analizando el tipo de empresas que fueron desde el punto de vista de la regulación a la que estuvieron sometidas por el Estado, de la estructura de su propiedad y del control de su gestión así como utilizando algunos elementos de las teorías de la agencia y de la regulación positiva.

\section{ABSTRACT}

Unlike two big European tobacco monopolies - the French monopoly and the Italian one-, which almost always were managed by the State, the management of Spanish tobacco monopoly was leased out for over a century to two companies very related: the Compañia Arrendataria de Tabacos (1887-1945) and Tabacalera (1945-1998). This paper provides an explanation of this situation analising the kind of companies they were from the standpoint of State regulation, ownership structure and management control and also using some principles of the Agency's Theory and the Economic Regulation's Theory. 


\section{INTRODUCCIÓN ${ }^{1}$}

En 1887, la Hacienda pública española puso fin a siglo y medio de gestión directa del monopolio de tabacos cediéndola, mediante un contrato de arrendamiento, a la Compañía Arrendataria de Tabacos (en adelante CAT), una sociedad anónima de capital privado constituida expresamente para tal fin. Esta empresa renovó en tres ocasiones (1896, 1900 y 1921) su relación contractual con la Hacienda, conservando ininterrumpidamente la gestión del monopolio hasta 1945. En esta fecha, tras adjudicársele de nuevo en concurso esta gestión por un periodo de veinticinco años, creó al efecto Tabacalera, S. A. (en adelante Tabacalera), una nueva empresa privada en cuyo accionariado el Estado ocupó, no obstante, una posición destacada. En 1971, esta empresa renovó su relación contractual con la Hacienda y en 1985 la ajustó a las directrices reguladoras de los monopolios fiscales imperantes en la entonces Comunidad Económica Europea. Finalmente, en 1998 se ha eliminado el monopolio de tabacos, salvo en el comercio al por menor, y Tabacalera ha sido completamente privatizada. De manera que la gestión del monopolio de tabacos ha permanecido cedida sin interrupción durante más de un siglo a dos empresas, controladas casi todo el tiempo por la iniciativa privada y muy vinculadas entre sí, que la han ejercido de forma consecutiva ${ }^{2}$.

La dilatada permanencia de este modo de gestión del monopolio de tabacos es, pues, un fenómeno de la historia económica española que necesita ser explicado, pues contrasta tanto con el carácter experimental que pretendió darle al primer arrendamiento en 1887 el entonces ministro de Hacienda, el liberal Joaquín López Puigcerver, con objeto de incrementar su capacidad recaudatoria, como con las cambiantes formas de gestión que ofrecen durante el mismo período otros monopolios fiscales españoles, como el de cerillas o el de explosivos ${ }^{3}$. El contraste se observa también cuando se compara el caso español con la experiencia que proporciona

${ }^{1}$ Este trabajo forma parte de una investigación patrocinada por la Fundación Tabacalera sobre la historia de esta empresa y de su antecesora, la Compañía Arrendataria de Tabacos. La investigación ha sido dirigida por Francisco Comín y Pablo Martín Aceña y ha contado con la colaboración de Daniel Díaz, Doria González, Fernando del Rey y la mía propia. Ninguno de ellos, sin embargo, es responsable de los posibles errores o deficiencias que puedan encontrarse en el texto. Asimismo, agradezco las observaciones hechas por un evaluador anónimo que han servido para mejorar la versión final.

2 Véase la historia de todo este proceso en Comín y Martín Aceña (1999).

${ }^{3}$ Véase en Comín (1991), pp. 150-151, dichas formas de gestión y el tiempo en el que estuvieron vigentes. 
la gestión de otros monopolios de tabacos de países como Francia o Italia, que en varias ocasiones fueron objeto de atención preferente por parte de los reguladores del Ministerio de Hacienda español. En el caso francés, el monopolio estuvo gestionado siempre por el Estado, bien directamente, bien mediante el SEITA, un establecimiento público de carácter industrial y comercial dotado de autonomía financiera que se creó en 1926. En el caso italiano, la gestión del monopolio fue cedida a la iniciativa privada entre 1868 y 1883, experiencia en la que se basó López Puigcerver para proceder al arrendamiento del monopolio español en 1887. Sin embargo, a diferencia de España, el Estado italiano lo recuperó en 1884 y lo gestionó de manera directa hasta 1926 cuando se creó con este fin la Amministrazione Autonoma dei Monopoli di Stato, un establecimiento público dependiente del Ministerio de Hacienda ${ }^{4}$.

Este trabajo tiene por objeto analizar la naturaleza empresarial de la CAT y Tabacalera, la estructura de su propiedad y el control de su gestión, y presentar, a partir de este análisis, una explicación selectiva de la permanencia de la gestión arrendada del monopolio de tabacos durante más de un siglo. Para ello, se estudian las principales relaciones a que dio lugar el arrendamiento de la gestión del monopolio entre la Hacienda pública, como titular del mismo, y la empresa encargada de gestionarlo a la luz de las aportaciones de la teoría de la agencia y de las teorías positivas de la regulación que, teniendo en cuenta los incentivos de los agentes en presencia, predicen la influencia del regulado en el regulador y la posibilidad de la «apropiación» o «captura» de éste orientando los efectos de su acción reguladora en beneficio de aquél ${ }^{5}$.

Los sucesivos contratos de arrendamiento -0 concesiones ${ }^{6}$ - de la gestión del monopolio de tabacos $(1887,1896,1900,1921,1945$ y 1971) establecieron una relación de agencia básica. En ella, el principal, la Hacienda pública, propietaria del derecho a explotar en régimen de monopolio la fabricación, distribución y venta de labores de tabaco, cedió la gestión

4 Véase una síntesis de éstas y otras formas nacionales de gestión de los monopolios de tabacos en Comin y Martín Aceña (1998), pp. 51-56.

5 Sobre los contenidos esenciales de la teoría de la agencia pueden verse: Jensen y Meckling (1976), Fama y Jensen (1983) y Fama (1984). Una aplicación interesante de estos contenidos a la empresa pública se encuentra en Fernández (1994). Sobre la teoría de la regulación, destaca el trabajo de Stigler (1971) y la sistematización hecha por Posner (1974) y Peltzman (1993) de las aportaciones analiticas disponibles en este campo.

6 Para las diferencias jurídicas entre el contrato de arrendamiento y la concesión en el caso de este monopolio, véase Albiñana (1987) y Martín-Retortillo y Salas (1969), pp. 50-55. 
de este derecho a un agente, la CAT primero y Tabacalera después. Como contrapartida al desempeño de esta función, estas empresas recibieron unas compensaciones económicas, que en esencia consistían en una participación en los beneficios del monopolio y en determinadas exenciones tributarias, particularmente importantes en la época de la CAT. Mientras que para el principal el incentivo de la cesión estaba en la obtención de mayores ingresos asociados a la mejor explotación del monopolio ${ }^{7}$, para el agente existía un interés especial en prolongar en el tiempo una relación contractual que le aseguraba altos beneficios con un riesgo prácticamente nulo. De ahí que desarrollase una estrategia tendente a evitar la celebración de concursos o subastas de la gestión del monopolio que pusiesen en peligro su posición privilegiada ante eventuales competidores atraídos por los altos beneficios.

La Hacienda pública, además de ceder a la empresa gestora el uso de los activos destinados a la explotación, regulaba la forma en que debían ser empleados (establecía ciertas obligaciones) así como los restantes aspectos básicos implicados en la actividad del monopolio, como la clase y el precio de labores a producir y vender, y fijaba el procedimiento a seguir para controlar la gestión del agente, tarea reservada al Gobierno, pero sobre todo al ministro de Hacienda de turno y a un representante del Estado nombrado por aquél. Esto supone, cuando menos, la aparición de dos nuevas relaciones de agencia asociadas a la actividad de control de la gestión de la compañía arrendataria por parte de la Hacienda. De un lado, la del ministro como agente de ésta encargado de controlar (autorizar) determinadas decisiones y acuerdos de la compañía; de otro, la del representante del Estado como agente del Gobierno encargado del control externo (supervisión) de la gestión diaria de ésta. Es decir, nos encontramos ante una cadena de relaciones de agencia en la que los objetivos del principal -incrementar los ingresos públicos procedentes del monopolio de tabacos, para evitar otras alternativas de recaudación por la vía de la creación de nuevos impuestos o la elevación de los existentespueden aparecer mezclados con objetivos particulares de los dos agentes citados, tales como la permanencia en el puesto (delegado del Gobierno), la posibilidad de optar a un cargo de dirección en la compañía al cesar

7 Come monopolio fiscal, la finalidad recaudatoria es consustancial a su existencia. Comín (1991), Albiñana (1987) y Martin-Retortillo y Salas (1969). El motivo principal de su arriendo a la iniciativa privada en 1887 fue incrementar los ingresos que el Estado obtenía de esta Renta (Torres, 1998). 
en la Administración o simplemente la existencia de criterios de oportunidad política.

Por el lado de la empresa arrendataria existe a su vez otra relación de agencia en virtud del grado de separación entre su propiedad y gestión, viéndose los accionistas (principal) abocados a diseñar mecanismos de control interno de la actuación de la gerencia (agente). Como veremos en los siguientes epígrafes, la gestión de la CAT y de Tabacalera estuvo asignada a un consejo de administración y a un director gerente durante casi todo el período de tiempo considerado. En consecuencia, resulta esencial determinar el grado de concentración o de dispersión de su accionariado y la forma cómo estaba representado en el consejo, pues a partir de ahí se puede apreciar el tipo de control - y la eficacia del mismo- que aquél ejercía en las decisiones de éste. Asimismo, es necesario conocer la vinculación del director gerente con el consejo y las formas de control de su actuación por parte de este órgano.

El trabajo, por tanto, se organiza sobre tres aspectos: 1) los procedimientos establecidos en los sucesivos contratos a través de los que la Hacienda controlaba la gestión del monopolio encomendada a la empresa arrendataria, 2) la composición del accionariado de la CAT y de Tabacalera, y 3) los órganos responsables de la gestión de estas compañías y la vinculación de sus miembros con el accionariado. Cada uno de ellos será estudiado sucesivamente en los tres epígrafes siguientes, analizando en un epígrafe posterior las relaciones que se establecieron entre los representantes de la Hacienda y los gestores de la CAT y Tabacalera en la práctica diaria de la administración del monopolio, así como las estrategias que desarrollaron estos últimos para prorrogar la relación contractual cada vez que tocaba a su fin. Finalmente, unas conclusiones tratarán de sintetizar las principales aportaciones de este trabajo.

\section{EL CONTROL DE LA GESTIÓN ARRENDADA DEL MONOPOLIO DE TABACOS POR PARTE DE LA HACIENDA PÚBLICA}

El primer contrato de arrendamiento forma parte de la Ley de 22 de abril de 1887. En él se establecía que algunas decisiones del contratista deberian ser aprobadas por el Gobierno o por el ministro de Hacienda para que pudieran aplicarse, aunque el máximo grado de control recaía 
en el primero ${ }^{8}$. Asimismo, se creaba la figura del delegado del Gobierno como interventor de todas las operaciones que realizase el contratista en relación con el arriendo. El delegado, cuyo nombramiento era potestad del Gobierno, cumplía sus funciones en la sede central desde la que el contratista gestionaba el monopolio y tenía derecho, tanto él como los funcionarios a sus órdenes, a visitar las fábricas, almacenes y expendedurías, a examinar las materias primas y las labores, y a inspeccionar la contabilidad y los movimientos de caja. Además, los representantes del contratista quedaban obligados a facilitarle los datos, explicaciones e informaciones que requiriese y a exhibirle la documentación justificativa de las operaciones realizadas.

Este modelo de control sufrió cambios notables en el contrato de $1896^{9}$. Básicamente, la nueva regulación avanzaba en la línea de establecer una gestión cointeresada del monopolio entre la Hacienda y la CAT ${ }^{10}$, siguiendo el modelo italiano del período 1868-1983, que entre otras cosas implicaba un aumento considerable de las partidas que entraban a considerarse como gastos en la liquidación anual de los rendimientos del monopolio. Esto supuso una ampliación del control de la gestión reservado a la Hacienda, en tanto que ahora fue necesario autorizar y supervisar un número mucho mayor de acuerdos del consejo de la CAT. Lo que sin duda contribuyó a que esta función, esencialmente administrativa - materializada vía expediente con su correspondiente autorización por medio de Real Orden-,

${ }^{8}$ El Gobierno se reservaba, además de la capacidad de imponer multas por determinadas faltas o infracciones del contratista, la competencia para rescindir el contrato en todo momento sin alegar causa justificativa, o si se daban determinadas circunstancias. Compañía Arrendataria de Tabacos (1887), pp. 5-23.

${ }^{9}$ Este contrato formaba parte de la Ley de 30 de agosto de 1896, promulgada para obtener recursos extraordinarios para el Tesoro público con el fin de financiar el esfuerzo militar que exigía la guerra de Cuba. Archivo de Tabacalera (AT), sig. Reglamentos 6, Ley de 30 de agosto de 1896 aprobando las condiciones para la renovación del contrato con la Com. pañia Arrendataria de Tabacos.

${ }^{10}$ Eleuterio Delgado (1892), pp. 551-561, que era el director gerente de la CAT en estos años, concebía la gestión cointeresada, o de participación de beneficios, como una forma equilibrada de reconocer la aportación de los dos socios: el Estado, como dueño del monopolio, tenía derecho a ejercer un control amplio de la gestión del mismo y a recibir una renta (canon) fija más una participación en los beneficios, mientras que la CAT debía recibir el interés del capital que tenía comprometido más una participación en los beneficios para remunerar su responsabilidad en la gestión. En una línea de interpretación parecida a ésta, Albiñana (1987), p. 384, recalca la característica de la gestión interesada como propia de los monopolios fiscales, lo que permite hablar de una relación de concesión más bien que de arrendamiento. No obstante, estos dos términos se han empleado en la experiencia española de los monopolios fiscales y administrativos con mucha ambigüedad, a juicio de Martín-Retortillo y Salas (1969), pp. 52-55. 
se burocratizase mucho más a base de extender dicho procedimiento a un sinfín de aspectos de la gestión diaria ${ }^{H}$.

La novedad más llamativa del contrato de 1896 fue que al presidente de la CAT lo nombraba el Gobierno y ejercía al tiempo las funciones de delegado de éste, figura que pasaba a denominarse desde ese momento representante del Estado. Sus atribuciones aumentaron sensiblemente. Podía suspender, dando cuenta al ministro de Hacienda, los acuerdos del consejo en relación con la gestión del monopolio, presidía las juntas de accionistas de la CAT y las comisiones ordinarias o extraordinarias de su consejo, autorizaba los balances, memorias y demás documentos a formar según sus estatutos y reglamentos, y ejercía la alta inspección de todos los servicios a cargo de esta empresa.

Por lo demás, el Gobierno conservó la capacidad de imponer al arrendatario multas por determinadas faltas o incumplimiento de sus obligaciones y, en última instancia, la de rescindir el contrato. Sin embargo, estas dos competencias estaban definidas ahora de manera más favorable para la CAT, pues se le reconocía el derecho a ser oída previamente y la posibilidad de interponer recurso contencioso-administrativo contra las decisiones firmes. De todas formas, como ocurría en el contrato de 1887 , en el de 1896 la posibilidad real de que se llegase a la rescisión era remota, ya que en ninguna de las leyes que sirvieron para su aprobación se previó la dotación del crédito necesario para el caso de que el monopolio revertiese a la Hacienda antes de finalizar el período de vigencia del contrato.

Tal contingencia fue prevista por primera vez en el contrato de 1900 , redactado como consecuencia de la subida del precio de las labores impuesta por el Gobierno en el marco de las reformas tributarias del ministro Fernández Villaverde ${ }^{12}$. En este contrato y en su reglamento de aplicación, ambos con un contenido regulatorio mucho más minucioso y prolijo que los anteriores, se mantuvieron e incluso se incrementaron los procedimientos administrativos de control de la gestión del monopolio por parte de la Hacienda. No obstante, se rectificó la extralimitación y confusión de competencias que significaba la unión en una misma persona de las fun-

1 El contrato de 1896 fue el primero al que se le añadió un reglamento de aplicación, que concretaba con gran minuciosidad su contenido. Esta práctica se hizo habitual en los siguientes contratos firmados por la CAT. Los reglamentos de aplicación se elaboraron habitualmente entre el representante del Estado y el consejo o el director de la CAT, por lo que resultó ser una vía por la que ésta trató de contrarrestar los eventuales perjuicios que le deparó la discusión parlamentaria de los contratos.

${ }_{12}$ AT, sig. Reglamentos 6, Real Decreto de 20 de octubre de 1900 aprobando el nuevo contrato entre el Estado y la Compañia Arrendataria de Tabacos. 
ciones de representante del Estado y de presidente de la CAT. En tal sentido, el Gobierno - y en particular el ministro de Hacienda- recuperó la facultad de autorizar previamente los principales actos de gestión de la CAT, incluyendo ahora también la de aprobar los estatutos de ésta y el nombramiento de los miembros de su consejo de administración, y se restableció una representación del Estado separada por completo de los órganos de dirección de la CAT y a las órdenes directas del ministro. No obstante, el representante del Estado siguió participando en las reuniones del consejo pero sin voto y conservó la capacidad de protestar, suspender y poner en conocimiento del ministro los acuerdos de este órgano que fuesen contrarios a los intereses del Gobierno o al contenido del contrato. El modelo de gestión cointeresada desapareció y se recuperó la filosofía del contrato de 1887: el monopolio lo administraba la CAT con intervención del representante del Estado y bajo la superior autoridad del ministro de Hacienda.

El contrato de 1900 proporcionó un modelo de control de la gestión del munopolio por parte de la Hacienda, que se consolidó firmemente en los años siguientes contribuyendo a rutinizar esta función e incluso la gestión misma del monopolio. Su arraigo en la práctica diaria y su aceptación por ambas partes (Ministerio de Hacienda y consejo de la CAT) llegó a ser tal que en el contrato de 1921 se mantuvo sin grandes modificaciones ${ }^{13}$. De hecho, las que se introdujeron en esta fecha aumentaron la tutela ejercida por la Hacienda y las competencias del representante del Estado, que desde entonces intervino y aprobó también las liquidaciones anuales de los resultados del monópolio - antes competencia del ministro- y tuvo capacidad para proponerle a éste, con la aceptación de la empresa, las reformas y mejoras que considerase oportunas para el desarrollo del monopolio. Esto último supuso una brecha en las funciones propias de la empresa arrendataria, por la que el Estado pudo entrar en la gestión del monopolio dejando patente su propósito de ir más allá del mero control externo de ésta, por muy amplio que fuese ${ }^{14}$.

Esta tendencia se afianzó veinticinco años después en un ambiente mucho más propicio a las iniciativas estatales de carácter empresarial, tanto

${ }^{13}$ Ibid., sig. Reglamentos 20, Ley de 29 de junio de 1921 sobre arrendamiento del monopolio de tabacos y servicios del timbre y cerillas. Contrato entre el Estado y la Compañia Arrendataria de Tabacos de 15 de octubre de 1921.

${ }^{14}$ De forma complementaria a esta incursión en la gestión del monopolio, el Estado se reservó una participación en los beneficios de la CAT cuando sobrepasasen el 10 por 100 de su capital social. 
más después de haber mediado la experiencia de creación en 1927 de un nuevo monopolio fiscal, el de petróleos, cuya administración se arrendó por concurso a la CAMPSA ${ }^{15}$. Cuando Tabacalera comenzó su andadura en 1945, el Estado no sólo conservó sus amplias competencias de control de la gestión del monopolio, sino que se reservó también el derecho a colaborar en la gestión misma. Así lo recogieron tanto la Ley de bases de 1944 como el contrato de $1945^{16}$ al decir que el monopolio de tabacos era un «servicio público patrimonializado», cuya explotación correspondia a Tabacalera «con la colaboración e intervención del Estado» y «con subordinación al interés público». El representante del Estado —rebautizado otra vez delegado del Gobierno y nombrado por éste- tuvo capacidad para vetar los acuerdos de la junta de accionistas y de los órganos de dirección de esta empresa, así como para tomar ciertas iniciativas relacionadas con la administración diaria ${ }^{17}$. Además, las competencias del ministro de Hacienda se extendieron más allá de la aprobación del nombramiento de los miembros del consejo y del director gerente, incluyendo también su destitución. Por último, aumentaron los motivos de rescisión del contrato debidos a infracciones cometidas por la compañía gestora y se introdujo uno nuevo, por el que el Estado podría rescindirlo sin indemnización «por graves razones de conveniencia del interés público» ${ }^{18}$.

${ }^{15}$ Véase Tortella (1994), pp. 297-300, para algunos detalles del control de la gestión de este monopolio por parte del Estado. El modelo de arrendamiento del monopolio de petróleos se inspiraba en el de tabacos, pero iba más allá al formar parte el Estado del capital de CAMPSA («Compañía Arrendataria del Monopolio de Petróleos, S. A.»), correspondiéndole, por tanto, recibir una proporción de sus beneficios y elegir una parte de sus consejeros. Esta novedad serviría de referencia a los responsables del Ministerio de Hacienda en 1944-1945 para aplicarla al nuevo arrendamiento del monopolio de tabacos. En este sentido, puede afirmarse que el modelo de arrendamiento del monopolio de petróleos de 1927 es el eslabón que enlaza el modelo de arrendamiento del monopolio de tabacos de 1921 con el de 1945, trayecto en el que el Estado dio un salto cualitativo en el control de su gestión por la via de introducirse en el capital y en la gestión interna de la empresa arrendataria.

${ }^{16}$ AT, sig. Reglamentos 27, Monopolio de Tabacos y Servicios Anejos: Disposiciones sobre su creación y funcionamiento, Madrid, 1945. Y Contrato para la explotación y administración del Monopolio de Tabacos y Servicios Anejos, aprobado por Decreto de 3 de marzo de 1945, Madrid, 1945.

17 Se le reconocían derechos de iniciativa y propuesta asi como capacidad para promover la formación de comisiones mixtas para el estudio y resolución de asuntos para los que se requiriese la máxima eficacia y rapidez en su tramitación. En los estatutos de Tabacalera de 1945 se le atribuyó incluso competencia para solicitar la reunión del consejo y de la junta extraordinaria de accionistas cuando lo considerase necesario.

${ }^{18}$ Este supuesto de rescisión era parecido al existente en los contratos anteriores, según el cual el Gobierno podría dar término al arrendamiento sin expresar causa. No obstante, 
El contrato de 1971, integrado en una ley cuyo proyecto inicial tenía la pretensión de ordenar la política tabaquera nacional ${ }^{19}$, siguió por estos mismos derroteros fortaleciendo la presencia del Estado en los dos aspectos antes señalados. Así, por ejemplo, el Gobierno podía obligar a Tabacalera a ampliar su capital en las condiciones que determinase, si así lo demandaban las necesidades de la política tabaquera o lo requiriese la «adecuada» gestión del monopolio. Y en cuanto al delegado del Gobierno, que desde 1961 tenía rango de director general con importantes medios a su disposición para ejercer con mayor eficacia sus competencias fiscalizadoras, reunía numerosas y variadas funciones entre las que destacaban por su novedad la de administrar los bienes del Estado adscritos al monopolio y la de coordinarse con los consejeros representantes del capital público para la mejor defensa de los intereses estatales. Se confirmaba también su iniciativa para la convocatoria de la junta de accionistas y del consejo de administración cuando lo considerase necesario.

Finalmente, la adaptación del monopolio de tabacos al ordenamiento comunitario tras la incorporación de España a la CEE en 1986 quedó regulada en la Ley 38/1985, de 22 de noviembre, del Monopolio Fiscal de Tabacos. Se liquidó el contrato de 1971 y el Estado traspasó a la nueva Tabacalera los bienes adscritos al monopolio de tabacos a cambio de aumentar su participación accionarial por medio de una ampliación de capital hecha en 1986. El delegado del Gobierno continuó ejerciendo las mismas competencias de tutela y control externo de la gestión del monopolio ${ }^{20}$, mientras que la Dirección General del Patrimonio siguió encargándose de los derechos del Estado como accionista mayoritario de esta empresa. Pos-

el supuesto sustituido se reintrodujo en el contrato de 1971, probablemente pensando en dar al Estado capacidad de maniobra ante una futura integración en la CEE, en la que se exigiese la abolición del monopolio.

${ }^{19}$ En el texto finalmente aprobado por las Cortes franquistas con el título de Ley 10/1971, de 30 de marzo, sobre gestión del monopolio de tabacos y su coordinación con la politica tabaquera nacional se abandonó el objetivo inicial del Gobierno de establecer un completo marco regulador de la política tabaquera nacional, en el que se integrase la gestión del monopolio, por la diversidad de intereses implicados - sobre todo cultivadores peninsulares y fabricantes de tabaco canarios-, cuya consideración íntegra hacía más complicada y difícil la estabilidad del modelo de relación vigente entre el Estado y Tabacalera.

20) Tabacalera continuó gestionando el monopolio de fabricación de tabacos peninsulares y el de importación y distribución de tabacos manufacturados no comunitarios, mientras que el Estado recuperó el monopolio de venta al por menor - las expendedurías fueron desde entonces concesionarias directas de él一. Sólo se liberalizó la importación y comercio mayorista de tabacos elaborados de procedencia comunitaria. El Gobierno español actuó al respecto de la misma manera que lo habían hecho unos años antes sus homólogos francés e italiano ante los requerimientos de la Comisión Europea. 
teriormente, los requerimientos del Tratado de Maastricht han impuesto la eliminación de este monopolio en todo el ámbito de la Unión Europea, lo que ha ocurrido en España en 1998 al mismo tiempo que se privatizaba totalmente el capital de Tabacalera. En consecuencia, la intervención del Estado ha desaparecido y su papel se limita sólo a supervisar la existencia de condiciones de libre competencia en esta industria.

Así pues, puede decirse que desde 1945 Tabacalera, como empresa con un alto grado de regulación y con una participación mayoritaria del Estado en su capital, no se diferenciaba apenas de una empresa pública, aunque propiamente no lo era ni desde el punto de vista jurídico ${ }^{21} \mathrm{ni}$ desde el de la gestión diaria, pues, como veremos luego, hasta después de la firma del contrato de 1971 el Estado no hizo valer su mayoría en el capital para conseguir una representación equivalente en el consejo de administración y responsabilizarse, en consecuencia, de la gestión de la empresa.

\section{LA COMPOSICIÓN DEL ACCIONARIADO DE LA CAT Y TABACALERA}

La creación de la CAT fue precedida por una transacción entre el Ministerio de Hacienda y el Banco de España en el marco de las relaciones financieras existentes en 1887 entre ambas instituciones, lo que prefiguró la composición de su accionariado. En efecto, el deseo del ministro Joaquín López Puigcerver de que el arriendo del monopolio de tabacos no fuese a parar a manos de una entidad que no ofreciese la confianza y seriedad necesarias para gestionar un ingreso fiscal de esta magnitud - dada la experiencia de los arriendos de esta Renta en épocas anteriores ${ }^{22}$ - encontró su mejor aliado en el interés del Banco de España por ampliar sus relaciones con la Hacienda, eliminando así la posibilidad de que cualquier otra entidad pudiese hacerle la competencia en la prestación de servicios

${ }^{21}$ Véase Martín-Retortillo y Salas (1969), pp. 94-95.

${ }^{22}$ Durante la primera época del estanco del tabaco, aproximadamente la centuria siguiente a su establecimiento por las Cortes castellanas en 1636, su explotación se arrendó a particulares, pero esta fórmula resultó funesta para la Hacienda, a juicio de algunos tratadistas. Los arrendatarios adquirían el tabaco elaborado en las fábricas y se encargaban de su expendición, pero esto no impedía que compraran al contrabando la mayor parte del que se consumía con grave quebranto de los intereses de la Hacienda. Véase Toledano (1860), tomo II, p. 412. Más tarde, el contrato de arrendamiento de 1844 fue anulado al poco tiempo de entrar en vigor por la poca confianza que despertó el arrendatario en las nuevas autoridades gubernamentales. Véase Torres (1998), epígrafe 1. 
financieros a ésta. El compromiso del Banco de quedarse con el arriendo del monopolio tuvo como contrapartida la creación de una empresa encargada de gestionarlo, en cuyo capital tendría éste una participación mayoritaria para poder ejercer una «superior y decisiva vigilancia interviniendo con amplias facultades en su administración», además de la facultad de centralizar en sus cajas los movimientos de los fondos (tesorería) del monopolio ${ }^{23}$.

Una vez obtenido el arriendo del monopolio en el correspondiente concurso, el Banco de España se lo cedió a la CAT, empresa que él mismo se encargó de constituir como una sociedad anónima de crédito. A su destacada aportación al capital se añadió la que hicieron un grupo de entidades y personas interesadas en el negocio ${ }^{24}$. Sin embargo, en los meses siguientes todos los fundadores colocaron entre su personal, accionistas, clientes y socios una gran parte de las acciones de la nueva empresa en atención a los compromisos previamente contraídos. Estas ventas estuvieron favorecidas por la facilidad de transmisión de estos títulos, pues en seguida se convirtieron en acciones al portador, y por la gran expectación que despertaron dando lugar a un fenómeno especulativo de cierta magnitud. En consecuencia, se produjo una gran dispersión de la propiedad de los mismos y la emergencia de un amplio número de pequeños accionistas, que fue una característica esencial de la estructura del accionariado de la CAT.

Otra característica a destacar es la permanencia, durante toda la existencia de la empresa, del Banco de España como principal accionista, lo que le permitió controlar su gestión desde el principio hasta el fin. El banco emisor se quedó con 24.540 de las 60.000 acciones que se reservó en el momento de la constitución de la CAT. Las demás las vendió entre sus accionistas, empleados y clientes de toda España a través de su red de sucursales. Este paquete accionarial representaba el 20,5 por 100 del

${ }^{23}$ Archivo Histórico del Banco de España (AHBE), Secretaría, caja 667, Actas del consejo de gobierno del Banco de España, sesión del 11 de abril de 1887. El Banco de España sabía que los ingresos que proporcionaba la Renta de tabacos se venían destinando a pagar las cargas financieras de la deuda flotante del Estado, la mayor parte de la cual estaba en sus manos, por lo que mantener la tesorería de esta Renta en sus cajas era crucial para no correr ningún riesgo al respecto. Además, en la perspectiva de incrementar sus servicios financieros al Estado, el Banco llevaba un tiempo discutiendo sin éxito con el ministro de Hacienda las condiciones en las que se haría cargo de la tesorería de la Hacienda pública, lo que supondría la centralización en sus cajas de todos los cobros y pagos vinculados al presupuesto del Estado. Para más detalles, véase Torres (1998), epígrafe 3.2.

${ }^{24}$ La relación de fundadores de la CAT puede verse en Torres (1998), p. 80, y en Comín y Martín Aceña (1999), p. 105. 
capital social y permaneció inalterado hasta 1905 , en que se redujo a 21.000 acciones (el 17,5 por 100), manteniéndose así hasta la liquidación de la empresa.

El segundo mayor accionista fue la Sociedad Urquijo y Cía. - accionista, a su vez, del Banco de España-, que en 1918 se convertiría en Banco Urquijo, pero su participación no fue tan estable. De hecho, estuvo sujeta todos los años a modificaciones con una tendencia a reducirse a largo plazo. Así, en 1892 llegó al máximo con 10.484 títulos (8,7 por 100), contrayéndose después de forma continua y alcanzando el nivel más bajo entre 1907 y 1916, años en los que estuvo en torno a los 3.000 (2,5 por 100). Una nueva recuperación hasta las 5.407 acciones en 1921 dejó paso a una acusada reducción en los diez años siguientes, en los que el número de títulos en poder de esta entidad bancaria se contrajo hasta los 1.490 en 1929 y 1930 . Por detrás de estos dos grandes accionistas no hay constancia de que existiese ningún propietario extranjero de relieve, siendo muy pocos los nacionales de alguna importancia - más de mil acciones-que ofreciesen una participación tan estable a lo largo de la existencia de la CAT.

La estructura accionarial de la CAT pasó a Tabacalera, pues no en vano esta empresa fue creada por aquélla, siendo la entrada del Estado en el accionariado de la última la novedad principal. En efecto, en 1945 la CAT ganó en concurso la concesión del monopolio de tabacos y servicios anejos, pero quedó obligada a crear una nueva sociedad para gestionarlo. Fue así como se constituyó Tabacalera con un capital de 287 millones de pesetas representado por 574.000 acciones nominativas, que habrían de estar siempre en manos de españoles, exigencia que no existió en el caso de la CAT pero que encajaba perfectamente en el contexto aislacionista de los años cuarenta. Se establecieron dos clases de acciones: las de la serie A (300.000 representativas de 150 millones) fueron suscritas por los accionistas de la CAT (250.000) y el resto (50.000) por un grupo de bancos y empresas adherido a la proposición que habia ganado el concurso (Banco Urquijo, Banco Hispano Americano, Banesto, Banco Central, Banco de Aragón, Banca March y Compañía Industrial Expendedora - familia Fierro-, anterior explotadora del monopolio de venta de cerillas); las de la serie B (274.000 representativas de 137 millones) se entregaron al Estado como contraprestación por los bienes de la Renta de tabacos que aportaba ${ }^{25}$.

${ }^{25}$ AT, sig. Reglamentos 27, Monopolio de Tabacos y Servicios Anejos: Disposiciones sobre su creación y funcionamiento, Madrid, 1945, pp. 47-50. Y Contrato para la explotación 
Como puede observarse en el Cuadro 1, la participación del Estado en el capital de Tabacalera representó casi la mitad desde su constitución hasta los años ochenta, en que sobrepasó esta cuantía. Los contratos de 1945 y de 1971 le reconocieron el derecho a suscribir en las ampliaciones de capital el número de acciones de la serie $\mathrm{A}$ - estas operaciones sólo afectaron a dichos títulos- que le correspondiesen por su participación en el mismo. El contrato de 1971 determinó, por añadidura, que la participación del Estado en el capital sería siempre mayoritaria y, con este propósito, la Ley de este año reguladora del monopolio estableció que el Estado compraría todas las acciones que los accionistas privados le ofreciesen, operación que se saldó con un evidente fracaso, pues no consiguió superar la barrera del 50 por 100 del capital hasta los años ochenta.

Los dos mayores accionistas privados siguieron siendo el Banco de España y el Banco Urquijo ${ }^{26}$, cuya estabilidad en la cúspide del accionariado de Tabacalera garantizó la continuidad de la alianza que habían desarrollado para el control de la gestión de la CAT, aunque ahora el eje de esta alianza era el Estado en tanto que principal accionista. No obstante, la participación del Banco de España fue más importante que la del Banco Urquijo ${ }^{27}$ y se mantuvo sin grandes oscilaciones en su cuantía. Desde su nacionalización en 1962 puede considerarse que sus acciones en la compañía tabaquera fueron un complemento de las que poseía el Estado, aunque se mantuvieron patrimonialmente separadas. Después de la adaptación del monopolio a la normativa comunitaria en 1985 el Banco de España salió del accionariado de Tabacalera.

Una característica novedosa de la estructura de este accionariado en relación con la de su antecesora es la presencia entre los mayores accionistas de otros grandes bancos nacionales, como Banesto, que ya estuvo en la última época de la CAT, Banco Central y Banco Hispano Americano. Ade-

y administración del Monopolio de Tabacos y Servicios Anejos, aprobado por Decreto de 3 de marzo de 1945, Madrid, 1945, pp. 8-9.

${ }^{26}$ Sobre el alto porcentaje que tiene este Banco en 1946 respecto a los años siguientes ha de tenerse en cuenta que los datos de la fuente utilizada para ese año -la asistencia a la primera junta ordinaria de accionistas de Tabacalera - incluyen tanto acciones propias como representadas. Si restamos estas últimas, la participación de esta entidad sería aproximadamente del 8,8 por 100 , todavía bastante alta. Lo que tal vez deba explicarse por la vinculación que estableció en 1944 en el denominado «Pacto de las Jarillas» (véase Garcia Ruiz y Tortella, 1994, p. 421) con el Banco Hispano Americano, uno de los bancos participantes en la fundación de Tabacalera.

${ }^{27}$ Sin embargo, la participación directa del Banco Urquijo estaba reforzada por otras indirectas, como la que poseía «Industria y Navegación, S. A.», una sociedad de capitalización controlada por esta entidad bancaria. Muñoz (1969), pp. 512-516 y 583. 


\section{CUADRO 1}

Principales accionistas de Tabacalera (*), 1946-1985 (\%)

\begin{tabular}{|c|c|c|c|c|}
\hline & 1946 & 1963 & 1976 & 1985 \\
\hline 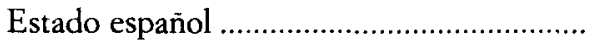 & 47,7 & 47,7 & 48,5 & 53,5 \\
\hline Banco de España.... & 7,7 & 7,6 & 6,2 & 6,0 \\
\hline Banco Urquijo ..... & 9,6 & 1,6 & 2,7 & 3,0 \\
\hline Financiera Fierro ... & 1,8 & & & \\
\hline 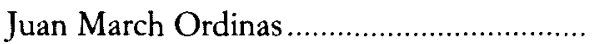 & 1,8 & & & \\
\hline 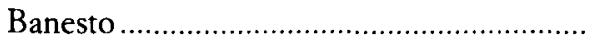 & 1,7 & 1,5 & & 1,0 \\
\hline Banco Central.. & 0,8 & & 0,7 & \\
\hline C. G. de Tabacos de Filipinas..................... & & 1,3 & & \\
\hline Banco Hispano Americano............................. & & 1,3 & & \\
\hline «Industria y Navegación, S. A.».................. & & 0,9 & 0,6 & \\
\hline «Mediterránea de Inversiones, S. A.»......... & & 0,8 & 1,3 & 1,3 \\
\hline Conf. Esp. de Cajas de Ahorros................... & & & 0,6 & 1,9 \\
\hline Hispano Americana de Valores Mobil. ....... & & & 0,6 & \\
\hline 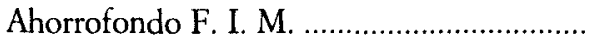 & & & 0,5 & \\
\hline 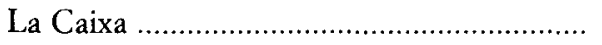 & & & & 5,5 \\
\hline
\end{tabular}

(*) Poseedores de más del 0,5 por 100 del capital.

FUENTE: Datos del AT, legajo 15.671, Relación de señores accionistas asistentes a la junta general de «Tabacalera, S. A.» del día 23 de junio de 1946; legajo 7.580, «Tabacalera, S. A.». Registro general de acciones. 1963; legajo 7.573, «Tabacalera, S. A.». Censo de accionistas por orden alfabético al 5 de mayo de 1976. Los datos de 1985 proceden de la información suministrada por el Departamento de Bolsa de Tabacalera.

más, debido a la aparición de las sociedades de inversión y de cartera desde el decenio de 1960, estos bancos pudieron aumentar de manera indirecta su participación en virtud del control que ejercieron sobre algunas de ellas ${ }^{28}$. Entre las razones que explican esta notable presencia bancaria se encuentra la relacionada con la posibilidad de participar en las operaciones crediticias del monopolio y en su servicio de tesorería, que ya no fue competencia exclusiva del Banco de España como en tiempos de

${ }^{2 \times}$ Esta suposición puede resultar especialmente relevante en el caso de que «Mediterránea de Inversiones, S. A.» (véase Cuadro 1) fuese una sociedad de cartera del Banco Rural y Mediterráneo, muy vinculado al Banco Urquijo e indirectamente al Hispano Americano por lo dicho en la nota anterior (véase González, Sánchez y Torres, 1981, pp. 84-85). A este último hay que adscribirle probablemente, además, el control de «Hispano Americana de Valores Mobiliarios, S. A.». 
la $\mathrm{CAT}^{29}$. Ésta fue tal vez una contrapartida exigida por el grupo de bancos antes citado para prestar su apoyo a la proposición presentada por esta empresa al concurso de adjudicación del monopolio en $1945^{30}$.

Así pues, teniendo en cuenta las variables habitualmente usadas en el análisis de la estructura de la propiedad de las empresas ${ }^{31}$, puede decirse que el Banco de España ejerció sobre la CAT un control minoritario, aun incluso añadiéndole la participación del Banco Urquijo. Este control fue posible por la extraordinaria dispersión del resto del accionariado. En Tabacalera, sin embargo, el accionariado estuvo más concentrado. Aunque el Estado no tuvo una participación accionarial superior al 50 por 100 hasta los años ochenta, su control fue mayoritario desde el principio porque los dos principales accionistas privados, que ya lo habían sido con la CAT, prolongaron su alianza tácita con el nuevo socio. Tabacalera fue desde su constitución una empresa de capital mixto, lo que suponía una notable diferencia con su antecesora, pero el capital privado siguió siendo mayoritario y esto fue sin duda un factor que favoreció que el control de la gestión continuase en manos privadas hasta 1971 con el beneplácito del Estado.

${ }^{29}$ De todas formas, parece que este asunto se modificó sobre la marcha durante el tiempo transcurrido desde la aprobación de la Ley de Bases de 1944 hasta la redacción del contrato de 1945. En la Ley seguía reservándose el servicio de tesorería y las operaciones de crédito del monopolio al Banco de España, mientras que en el contrato ambas cosas podían concertarse también con otros establecimientos bancarios mediante la correspondiente autorización del Ministerio de Hacienda. Tras la nacionalización del Banco de España en 1962, a la propia Tabacalera le interesó que su tesorería la gestionasen entidades de crédito privadas, porque el instituto emisor ya no remuneraba estas cuentas corrientes. Este argumento se esgrimió en la Comisión de Hacienda de las Cortes al dictaminar el proyecto de Ley de 1971.

311 El apoyo de los bancos le sirvió a la CAT para ofrecer mayores garantías al Estado de que podría aportar los 150 millones que correspondían a la iniciativa privada en el capital de Tabacalera. Téngase en cuenta que el capital social de aquella empresa era «sólo» de 60 millones.

${ }^{31}$ Son las tres siguientes: 1) tipo de control ejercido sobre la empresa (absoluto, si se poseen más del 80 por 100 de las acciones, mayoritario, si se tiene más del 50 por 100 , minoritario, si se tiene menos de este porcentaje, e interno, cuando nadie supera el 5 por 100), 2) grupo institucional que lo ejerce (familias, otras empresas nacionales o extranjeras, entidades financieras, sector público y mercado), y 3) grado de concentración de las acciones de los principales accionistas. Véase Galve y Salas (1997), p. 72. 


\section{LOS ÓRGANOS DE GESTIÓN DE LA CAT Y TABACALERA Y LA VINCULACIÓN DE SUS MIEMBROS CON LOS ACCIONISTAS}

En los estatutos originarios de la CAT, elaborados a imagen y semejanza de los del Banco de España por el primer director de esta empresa, el ex ministro de Hacienda Juan Francisco Camacho, se asignó su dirección y administración a un consejo, responsable ante la junta de accionistas, compuesto por un director, un subdirector y nueve consejeros. El primer consejo, inamovible durante los primeros cinco años, lo formaron cinco representantes del Banco de España, como principal accionista, y cuatro representantes de las demás sociedades y personas fundadoras. Pasado ese tiempo, los consejeros fueron renovados por la junta de accionistas en número de tres por año, determinándose por sorteo el turno de salida, pero esto no significó en ningún caso que se alterase la proporción de representantes del instituto emisor, que fue mayoritaria durante toda la vida de la Compañía ${ }^{32}$.

El consejo de administración tenía la facultad de nombrar por mayoría absoluta al director y al subdirector, lo que quiere decir que eran suficientes para ello los votos de los cinco representantes del Banco de España, pero para su separación del cargo se necesitaban dos tercios de los consejeros, es decir, seis votos. Ambos formaban parte del consejo, participando en sus reuniones - plenarias y de comisión - con voz y voto, y el primero de ellos, además, lo presidía en tanto que gerente de la Compañía. El segundo lo sustituía en sus funciones y ejercía las atribuciones que le delegase.

${ }^{32}$ La junta de accionistas elegía a los consejeros «a pluralidad de votos» de los accionistas presentes. Tanto en este caso como en la adopción de los demás acuerdos se exigía el respaldo de la mayoría absoluta de los accionistas presentes y de las acciones por ellos representadas, primando esta segunda mayoría cuando no coincidían las dos. Lo que garantizaba en último extremo el control de los acuerdos de la junta por los principales accionistas. La junta de accionistas elegía también cada año a cinco consejeros supernumerarios - desaparecieron en 1901 - para cubrir las ausencias que se produjesen en el consejo a lo largo del año y así evitar que se pudiese paralizar su actividad por falta del número suficiente de miembros para adoptar los acuerdos. Habitualmente, la junta reeligió a los consejeros a los que les correspondía salir según el turno establecido. Sólo cuando se producía una vacante, sobre todo por fallecimiento, se elegía a una nueva persona, que por lo general representaba los mismos intereses accionariales que su predecesora. Además, solía tener alguna familiaridad con la actividad del consejo por proceder del referido grupo de los consejeros supernumerarios. Todo esto contribuyó a que, en general, la permanencia de los consejeros fuese dilatada, proporcionando gran estabilidad al funcionamiento de este órgano. 
La trasposición casi literal de las figuras del gobernador, subgobernador y consejo de gobierno del Banco de España al diseño de la alta jerarquía directiva de la CAT propició una concentración de funciones y de poder en el director, que era al mismo tiempo gerente y presidente de la CAT. En consecuencia, no quedaron bien delimitadas y separadas las funciones de dirección, representación, administración y ejecución, por lo que muy pronto se planteó la necesidad de una reforma de los estatutos tendente a separar las figuras de presidente y director gerente así como las funciones propias del consejo de las que debían ser privativas de este último, a fin de que la división del trabajo propiciase una gestión más rápida y eficaz.

Esta reforma tuvo lugar en $1894^{33}$ y, tras ella, el consejo de administración mantuvo el mismo número de miembros, si bien su presidente dejó de ser la misma persona que el director gerente. Éste continuó en el consejo con voz y voto, pero el subdirector dejó de formar parte de él. Según los nuevos estatutos, el presidente, el vicepresidente - de nueva creación- y el director gerente, a los que se les exigió el depósito de 100 acciones de la CAT para responder de su gestión ${ }^{34}$, eran nombrados por el consejo por mayoría absoluta de votos, pudiendo ser cesados por igual procedimiento salvo en el caso del último, cuyo cese era competencia del presidente. Éste se convirtió en la principal figura jerárquica de la Compañía y asumió la alta representación de la misma ante terceros, en especial ante el Gobierno, aspecto que era de tal relevancia en el caso de la CAT por la naturaleza de su negocio que, en aras de conseguir la mayor armonía con el partido gobernante, motivó una alta rotación de personas en este cargo en particular desde su fundación hasta $1901^{35}$ (véase el Cuadro 2). Al consejo se le encomendaron las funciones de gobierno y administración, quedando el director gerente como responsable de dirigir la administración diaria bajo las orientaciones del consejo y de ejecutar los acuerdos de éste, lo que favoreció que en su nombramiento prevaleciesen sus cualidades profesionales frente a sus relaciones políticas, aunque éstas no fuesen relegadas del todo.

${ }^{3}$ AT, sig. Reglamentos 12, Estatutos de la Compañia Arrendataria de Tabacos, modificados por la Junta general extraordinaria de accionistas, celebrada el 29 de abril de 1894.

34 Esta obligación la tenían los consejeros desde la fundación de la CAT.

${ }^{35}$ Sobre la interrelación entre la coyuntura política - gobierno de turno-y el nombramiento o cese del presidente de la CAT y de otras sociedades semejantes a ella, puede verse El Economista, 13 de octubre de 1888 y 29 de agosto de 1891 ( «La acción de los Gobiernos en los bancos y sociedades»). Ni que decir tiene que esta interrelación existió desde el nacimiento de la CAT. Recuérdese que el primer presidente, Juan Francisco Camacho, a pesar de su oposición a la Ley de arriendo de 1887, era miembro del Partido Liberal, agrupación gobernante entre 1885 y 1890 . 
Este modelo de división de funciones entre el presidente, el consejo y el director gerente fue contaminado por el contrato de 1896, que determinó que al presidente lo nombraba el Gobierno y era al mismo tiempo el representante del Estado en la CAT. Aunque semejante disposición llevaba al extremo la posibilidad de conservar la «deseada armonía» en las relaciones del consejo con el Gobierno, lo cierto es que los consejeros de esta empresa no dejaron de considerar una extralimitación la unión de ambas figuras, cuyas funciones debían ser bien diferentes. Consiguieron que esto se rectificase en el contrato de 1900 .

Esta experiencia fue motivo de que, al reformarse los estatutos en $1901^{36}$, se reajustase el modelo de dirección y administración vigente en el sentido de recortar las atribuciones del presidente y de aumentar el poder y las funciones del director gerente. En efecto, estos estatutos, que estuvieron en vigor durante el resto de la existencia de la CAT, consagraron al consejo y al director gerente como los principales responsables de su dirección y administración. El consejo afianzó sus funciones de gobierno de la Compañía, mientras que la figura del director gerente, que era nombrado y cesado por este órgano, cobró mayor relevancia que antes, asumió más competencias directivas - algunas por delegación del consejo- y consiguió ciertas cotas de autonomía respecto de éste, al que siguió dando cuenta de su gestión diaria como miembro de pleno derecho (voz y voto). Además, su mayor protagonismo en la administración de la CAT quedó reforzado por la consolidación de la figura de los subdirectores, que le sustituían en sus funciones, algunas de las cuales podía también delegarles. El reforzamiento de la figura del director gerente motivó que, de nuevo, sus relaciones políticas volviesen a tener un gran peso en su nombramiento (Cuadro 2), reservando las competencias profesionales más bien para los subdirectores.

Los estatutos de Tabacalera de $1945^{37}$ atribuyeron el gobierno y administración de esta empresa a la junta de accionistas, al consejo de administración y a la dirección-gerencia y restante alta administración. A la junta de accionistas ${ }^{38}$ le correspondía la elección y renovación de los miembros del consejo en representación del capital privado (acciones de la serie A),

${ }^{36}$ AT, sig. Reglamentos 12, Estatutos de la Compañia Arrendataria de Tabacos, aprobados por Real Orden de 16 de febrero de 1901.

${ }^{37}$ AT, sig. Reglamentos 27, «Tabacalera, S. A.» (Compañía gestora del monopolio de tabacos y servicios anejos), Estatutos, Madrid, 1945.

${ }^{36}$ Los accionistas tenían tantos votos como acciones poseyesen o representasen, de manera que también aquí el peso de los grandes accionistas y, en particular, del Estado resultó determinante en la adopción de acuerdos. 
pues los representantes del capital público (acciones de la serie B) los elegía directamente el Gobierno. El consejo, que era responsable de su gestión ante la junta de accionistas y ante el Estado, estaba compuesto por 18 miembros, dos tercios (12) en representación del capital privado y un tercio (6) del Estado ${ }^{39}$. Era el máximo órgano de dirección y administración de la Compañía, cuya alta representación ostentaba. Elegía al presidente y a los vicepresidentes ${ }^{40}$ y nombraba y cesaba al director gerente, a los subdirectores, al secretario general y a los jefes de sección. Era, pues, un consejo muy semejante al de la última época de la CAT tanto por sus competencias como por su posición central en el gobierno de la nueva empresa. En cambio, el director gerente, que era miembro del consejo con voz pero sin voto y tenía como principales funciones dirigir la administración cotidiana y ejecutar los acuerdos del consejo y de sus comisiones, perdió parte del relieve que le atribuyeron los estatutos de 1901 al de la CAT.

Hasta el contrato de 1971 la presidencia siempre recayó en un representante de los principales accionistas privados procedentes de la CAT, lo que no deja de ser llamativo si se tiene en cuenta que el conjunto de su participación accionarial no superaba a la del Estado. Tanto en ella como en los puestos del consejo ocupados por el capital privado hubo una gran estabilidad, de manera que, como sucedió con su predecesora, la mayoría de las vacantes a cubrir se debieron al fallecimiento de sus titulares. Esta misma estabilidad es observable en el cargo de director gerente y algo menos entre los consejeros estatales, ya que al tratarse habitualmente de altos cargos de la Administración pública estuvieron sujetos a la movilidad derivada de los cambios de Gobierno habidos durante el franquismo.

Este modelo de dirección y administración tuvo su continuidad en los estatutos de 1971, aunque se introdujo un principio elemental que no se había aplicado hasta entonces: que la representación del capital estatal en el consejo sería proporcional a su participación accionarial. En tanto que el contrato de dicho año determinó que esta participación siempre sería mayoritaria la representación también lo fue. El nuevo con-

${ }^{39}$ Obsérvese que este reparto no era proporcional a lo que representaba la participación del Estado en el capital de Tabacalera, que era superior a un tercio. Hasta el contrato de 1971 no se subsanó esta clara subrepresentación del capital estatal en el consejo.

4t) Había dos, uno representando al capital privado y otro al capital estatal. Por su parte, el presidente llevaba la representación de la empresa en sus relaciones con los poderes públicos, excepto con los tribunales de justicia. 
sejo comenzó su andadura repartiendo a medias entre el Estado y el capital privado los 18 miembros que lo componían, pero desde 1979 hasta la adecuación del monopolio a la regulación comunitaria europea en 1985 el Estado incrementó sus consejeros hasta once, disminuyendo a siete los del capital privado. A éste se le otorgó siempre mayoría en las vicepresidencias - tres llegó a haber antes de 1977-, pero la presidencia recayó en una persona designada por el Ministerio de Hacienda, que era el encargado de ratificar el nombramiento de los consejeros privados así como de designar a los consejeros representantes del capital público. De todas formas, durante este período no fue infrecuente el trasvase de consejeros de la representación pública a la privada y viceversa, como si se tratase de piezas perfectamente intercambiables ${ }^{41}$. Por tanto, a partir del contrato de 1971, Tabacalera se convirtió en una empresa con mayoría de capital público, cuya gestión interna fue controlada finalmente por éste.

Así pues, la asignación de la gestión tanto de la CAT como de Tabacalera a un consejo de administración, que controlaba a su vez la actuación del director gerente, y la concentración de una parte significativa de sus capitales sociales en torno a un grupo de dos y tres grandes accionistas respectivamente, les facilitó a éstos el control de la gestión de ambas empresas, lo que se hizo con muy bajos costes de agencia. Precisamente, esta garantía de control suficiente y estable había constituido uno de los grandes objetivos a la vez que una condición exigida por el Banco de España al Gobierno para hacerse cargo del monopolio en 1887.

${ }^{41}$ Por poner un ejemplo, Carlos Rein Segura fue vicepresidente en representación del capital público en 1971-1973, pasando sin solución de continuidad a representar al capital privado en el mismo puesto en 1973-1979. Su trayectoria política y profesional era propicia para cambios de esta naturaleza: de procedencia falangista, durante muchos años había sido procurador a Cortes, consejero del Movimiento, director general y ministro, pero también consejero de los bancos Urquijo, Rural y Mediterráneo, Occidental y Exterior. Véase González, Sánchez, Torres (1981), anexos cap. V. 


\section{LAS RELACIONES ENTRE LOS REPRESENTANTES DE LA HACIENDA Y LOS GESTORES DE LA CAT Y TABACALERA. ESTRATEGIAS DE ESTAS EMPRESAS PARA CONSERVAR LA GESTIÓN DEL MONOPOLIO DE TABACOS}

Como ha señalado Comín (1991), los monopolios fiscales han constituido un eficaz expediente recaudatorio ${ }^{42}$ para las haciendas atrasadas (de pocos recursos y gestión sin modernizar), como ha sido la española en el siglo XIX y gran parte del Xx. A esta cualidad se añade su simplicidad de gestión en relación con la de otros impuestos. De ahí que durante mucho tiempo los ministros de Hacienda hayan sido pragmáticos, según este autor, y preferido este expediente fiscal frente a otras formas de imposición indirecta o directa, que les hubiesen acarreado sin duda mayores costes políticos tanto por el perjuicio ocasionado a los grupos de mayor renta y con mayor capacidad de presión política como por la resistencia de la burocracia a las reformas modernizadoras de la Administración pública.

En los años ochenta del siglo XIX las rentas estancadas representaban alrededor del 12 por 100 de los ingresos ordinarios del Estado, siendo la de tabacos la que aportaba casi el total de esta cifra. Su rendimiento garantizaba el pago de las cargas financieras de la deuda flotante, en poder del Banco de España, por lo que esta entidad estuvo en una posición negociadora inmejorable con el Ministerio de Hacienda para quedarse con el arriendo del monopolio de tabacos, cuando el Gobierno del liberal Sagasta se decidió por esta operación para resolver un problema urgente de déficit público. Como reflejaba el proyecto de ley de arriendo, se trataba de aumentar los ingresos del Estado para reducir el déficit de 60 millones de pesetas del presupuesto de 1886-1887, puesto que se había desechado la posibilidad de conseguir este objetivo incrementando los gravámenes de los impuestos y contribuciones existentes o creando otras nuevas, y tampoco se quería reducir el gasto ${ }^{43}$.

12 Su capacidad recaudatoria está relacionada con el impuesto indirecto implícito que establecen y con los beneficios extraordinarios del monopolio (Albinana, 1987). Para la inserción de este instrumento en la trayectoria de los sistemas fiscales en la Espana contemporánea, véase Comín (1996), cap. 2.

${ }^{43}$ Que el fin primordial del arriendo era cubrir las necesidades de la Hacienda, tanto las inmediatas como las previsibles a medio plazo sin elevar la deuda flotante, lo confirma también la obligación que la Ley de arriendo de 1887 impuso al contratista de anticipar al Estado, si éste lo solicitaba, una cantidad no superior a 8 millones de pesetas por cada 
Según las intervenciones del ministro López Puigcerver en el debate parlamentario, la mejora en el rendimiento del monopolio se conseguiría más rápidamente con el arriendo a particulares que continuando la gestión directa de la Hacienda ${ }^{44}$. Pero como la experiencia de los arriendos anteriores, sobre todo en el siglo XVII, había sido tan nefasta para la Hacienda, el ministro fijó un plazo corto - doce años- para confirmar sus ventajas o para recuperar la administración directa. Este carácter experimental lo confirma también el equilibrio que pretendía mantener la Ley de 1887 entre el Estado y el contratista, alejándose tanto de la libertad absoluta para el arrendatario, en la tradición de los contratos del siglo xvII, como de la sumisión completa a la Administración por una excesiva reglamentación. Pero con el transcurso de los años, además de perder su carácter experimental, la regulación contractual se hizo más amplia, haciendo posible que el Estado incrementase poco a poco su control sobre la gestión del monopolio y recuperase parte de los beneficios extraordinarios en manos del arrendatario, pero sin desalojarlo de aquélla ni privarlo de éstos. Y éste es, a mi juicio, el éxito cosechado por la estrategia desarrollada por el capital privado para mantener en sus manos durante casi un siglo la gestión de este monopolio fiscal. Veamos a continuación el conjunto de factores que, en mi opinión, contribuyeron al éxito de esta estrategia.

Las necesidades financieras de la Hacienda estuvieron presentes en todos los momentos en que se discutió la renovación del contrato de arriendo, por lo que nunca propiciaron la situación más adecuada para proceder a la reversión, sobre todo si la gestión arrendada garantizaba a la Hacienda un aceptable rendimiento del monopolio; pero tampoco dieron pie, salvo en 1944-1945, a plantear nuevos concursos de arriendo donde la competencia de otras firmas privadas hubiese favorecido la obtención de unos mayores ingresos para el Estado. Dado que el rendimiento del monopolio, al menos durante el periodo de gestión de la CAT, no fue netamente superior al conseguido en la última época de gestión directa ${ }^{45}$, ha de pensarse que en la pervivencia de su gestión arrendada hubo de influir no

año que faltase para finalizar el arriendo. No resulta extraño, por tanto, que los estatutos definiesen a la CAT como una sociedad anónima de crédito.

${ }^{+4}$ El contenido esencial de dichas intervenciones puede verse en Torres (1998), epígrafe 3.1

${ }^{45}$ Los datos que proporciona Comín (1991) indican que, aunque los ingresos brutos del monopolio crecieron prácticamente todos los años, el producto líquido se redujo desde el 70 por 100 de los ingresos brutos en 1887 al 60 en 1899, recuperándose después excepcionalmente hasta el 70 por 100 en 1915. En los años siguientes tuvo lugar un pronunciado descenso hasta el 50 por 100 en 1920 y una recuperación posterior que lo situó ligeramente 
poco la insuficiente voluntad que los respectivos gobiernos mostraron tanto en buscar un arrendatario más eficiente como en cancelar el arriendo a causa probablemente del limitado margen de maniobra - escaso poder de negociación- que tuvieron ${ }^{46}$.

De ahí el pragmatismo de que hicieron gala manteniendo contrato tras contrato al mismo arrendatario, lo que debe relacionarse, en primer lugar, con las urgencias financieras de los primeros años, puestas de manifiesto en los anticipos que se le exigieron a la CAT en los contratos de 1887 y 1896. En segundo lugar, con su interés por evitar los costes políticos derivados de acometer las reformas administrativas necesarias para mejorar la gestión directa del monopolio; reformas relacionadas principalmente, aunque no sólo, con la necesaria mecanización de la mayor parte de los procesos de la manufactura de las labores y la consiguiente reducción del número de operarias, así como con la introducción de una mentalidad más próxima al mercado que a los principios administrativos en todos los ámbitos de la organización del monopolio. Y, en tercer lugar, debe relacionarse también con la opción que tomaron los gobiernos de la Restauración y los que les siguieron después, incluidos los del período franquista, consistente en convertir al Banco de España en un elemento fundamental para la resolución de los problemas financieros de la Hacienda y del Tesoro públicos (banco del Estado) ${ }^{47}$. La confianza depositada por los responsables de ambas instituciones en el banco emisor para cubrir esta responsabilidad y la magnitud de estas relaciones financieras fueron dos factores esenciales para explicar cómo se entregó, primero, la gestión del monopolio de tabacos al Banco de España y cómo, después, resultó difícil separarlo de ella —si es que en algún momento se intentó algo así- debido tanto

por encima del 60 por 100 . Es decir, un rendimiento que no era claramente mejor al obtenido por la gestión directa de la Hacienda entre 1860 y 1886.

46 Es interesante observar que la reversión del monopolio al Estado ha sido vista como un problema por los gobiernos hasta fechas muy recientes. Así, durante la tramitación en la Comisión de Hacienda de las Cortes franquistas del provecto de ley de arriendo de 1971 se rechazó una enmienda, que pedía la reversión al Estado de la gestión del monopolio del timbre, por la necesidad que tendría éste de crear una extensa red de distribución al efecto. Archivo del Congreso de los Diputados, Secretaria General, leg. 1.050, núm. 1.

${ }^{4}$ Véase al respecto el trabajo de Tortella (1970), quien subraya (p. 305) cómo el Banco de España asumió decididamente la misión de allegar fondos para la Hacienda en detrimento de su función de instrumentalizar la política monetaria. En una reciente síntesis histórica sobre el banco emisor (Martín Aceña, 1997) este autor subraya que la función de banco del Estado, junto con la emisión de billetes, fue prácticamente la única función propia de un banco central que ejerció plenamente el Banco de España durante la centuria posterior al Decreto de 1874 . 
a que desde el principio esta actividad se convirtió en una parte no despreciable de las relaciones financieras del Banco con la Hacienda como a que cualquier eventual sustituto en la gestión del monopolio - particular o empresa privada - no podía sino despertar los más serios reparos por parte del instituto emisor y el riesgo para la Hacienda de poner en cuestión un modelo de relación con el Banco de España que le resultaba beneficioso desde su conversión en banco nacional. Es más, existe un cierto paralelismo en la forma y los períodos en que el Banco de España recibió del Estado la prórroga para ejercer sus funciones como banco nacional (1891, 1921 y 1946) y la prórroga o renovación de los contratos de arriendo del monopolio de tabacos con la CAT (la modificación de 1892 y la renovación de 1921) y con Tabacalera (el contrato de 1945), por lo que no puede descartarse que la continuidad del instituto emisor como responsable en último término de la gestión privada del monopolio de tabacos formase parte de las negociaciones con el Gobierno cada vez que éste reguló el marco en el que debían desenvolverse sus funciones de banco nacional. Así pues, la relación de agencia que estableció la Hacienda con el Banco de España en el arrendamiento del monopolio de tabacos no era algo aislado. Formaba parte de un conjunto de acuerdos financieros más amplio que era de vital importancia para la Hacienda y que, por este motivo, contribuyó a que dicha relación fuese estable y a que el agente gozase de una apreciable capacidad de negociación.

Las tres razones enunciadas, pero especialmente la última, apuntan, como sugiere el Cuadro 2, a que se intentó salvaguardar la estabilidad de las relaciones entre la Hacienda y las empresas arrendatarias del monopolio por medio del nombramiento para los más altos puestos de dirección de éstas (presidente y director gerente) de políticos de los partidos gobernantes con experiencia en el Ministerio de Hacienda y/o en la gobernaduría del Banco de España o directamente de destacados consejeros de esta entidad y de los bancos que apoyaban el control de la gestión de dichas empresas, como es el caso del Urquijo. Esta situación tendía a allanar los obstáculos que surgían en la gestión diaria del monopolio, facilitando el control externo encomendado al ministro de Hacienda y al delegado del Gobierno, al tiempo que convertía esta actividad en rutinaria. Pero también fue el cauce habitual y privilegiado a través del que ejerció su presión el arrendatario, poniendo a prueba y confrontando su poder de negociación con el de la Hacienda. Además, estos vínculos personales entre ambas partes no dejaban de ser una manifestación particular de un fenómeno más extenso de relaciones personales entre políticos y grandes empre- 


\section{CUADRO 2}

\section{Presidentes y directores gerentes de la CAT y Tabacalera, 1887-1998}

\begin{tabular}{lll}
\hline Nombres & Periodo & Observaciones (*) \\
\hline
\end{tabular}

\section{Presidentes y Dirs. gerentes}

Juan Francisco Camacho

Servando Ruiz Gómez

Amós Salvador Rodrigánez

Fernando Vida Palacio

Plácido de Jove y Hevia

Amós Salvador Rodrigánez

\section{Presidentes}

Venancio González Fernández

José García Barzanallana

Cayetano Sánchez Bustillo

Amós Salvador Rodrigáñez

José Cárdenas Uriarte

Luis de Ussía y Aldama

Alejandro Pidal y Mon

José Echegaray Eizaguirre

Juan Navarro-Reverter

Luis de Urquijo y Ussía

Ignacio Herrero de Collantes

Alfredo Zavala y Lafora

Pio Cabanillas Gallas

Alberto Monreal Luque

Gabriel Cañadas Nouvillas

Cándido Velázquez-Gaztelu

Miguel A. del Valle-Inclán

Bolaño

Germán Calvillo Urabayen

Pedro Pérez Fernández

César Alierta Izuel
1887-1887 ex ministro de Hacienda (liberal), ex gobernador del Banco de España.

1887-1888 ex director general de Rentas Estancadas, ex ministro de Hacienda (reformista).

1888-1890 diputado del P. Liberal.

1890-1890 diputado y senador del P. Conservador.

1890-1892 diputado y senador del P. Conservador.

1892-1894 diputado del P. Liberal.

1894-1895 ex ministro de Hacienda (liberal).

1895-1895 ex ministro de Hacienda (conservador).

1896-1897 ex gobernador Banco de España, diputado del

P. Conservador.

1897-1899 ex ministro de Hacienda (liberal).

1899-1901 ex ministro de Fomento (conservador)

1901-1908 socio de Urquijo y Cía, consejero del Banco de España.

1908-1913 ex ministro de Fomento, diputado del P. Conservador.

1913-1916 ex ministro de Hacienda y de Fomento (liberal).

1916-1923 ex ministro de Hacienda (conservador y liberal), diputado.

1923-1956 consejero del Banco Urquijo, consejero del Banco de España.

1956-1961 presidente del Banco Hispano Americano, consejero del Banco de España.

1962-1971 ex ministro de Hacienda, ex gobernador del Banco de España.

1971-1974 ex consejero del Banco de Crédito Industrial, del Banco Hipotecario y del INI.

1974-1982 ex ministro de Hacienda.

1982-1989

1989-1991 ex delegado del Gobierno en Tabacalera.

1991-1993

1993-1996

1996. 


\begin{tabular}{|c|c|c|}
\hline Nombres & Periodo & Observaciones (*) \\
\hline \multicolumn{3}{|l|}{ Directores gerentes } \\
\hline Eleuterio Delgado Martin & $1894-1898$ & diputado del P. Liberal. \\
\hline José Echegaray Eizaguirre & $1908-1913$ & ex ministro de Hacienda y de Fomento (liberal) \\
\hline Manuel Allendesalazar & $1913-1919$ & $\begin{array}{l}\text { diputado conservador, ex ministro de Hacienda, } \\
\text { ex gobernador del Banco de España. }\end{array}$ \\
\hline Pedro G. Fanjul & 1920-1922 & \\
\hline Francisco Bastos Ansart & $1922-1925$ & diputado. \\
\hline Luis de Albacete y Gil Zárate & $1925-1936$ & \\
\hline Luis de Urquijo y Ussía & $1936-1939$ & $\begin{array}{l}\text { consejero del Banco Urquijo, consejero del Ban } \\
\text { co de España. }\end{array}$ \\
\hline \multicolumn{3}{|l|}{ José Álvarez-Guerra Gutié- } \\
\hline rrez & $1939-1950$ & consejero del Banco de España. \\
\hline Juan Petrirena Aurrecoechea & $1950-1955$ & \\
\hline José Moreno Torres & $1956-1972$ & $\begin{array}{l}\text { consejero del Banco Exterior y del Banco Hipo- } \\
\text { tecario, procurador a Cortes. }\end{array}$ \\
\hline José Luis Perona Larraz & $1972-1974$ & \\
\hline Vicente Barberá Puig & $1974-1986$ & \\
\hline
\end{tabular}

(") Se recoge sólo información relevante sobre la vinculación con el partido gobernante, con la Hacienda y el sector público y con los principales accionistas de la CAT y Tabacalera antes o durante el desempeño del cargo. A partir de 1986 desaparece la figura de director gerente. En su lugar se crean varias direcciones generales cuyas competencias han variado bastante desde entonces.

Fuente: Datos de las Memorias de la CAT y Tabacalera, Mateo del Peral (1974a, b) y González, Sánchez y Torres (1981).

sas, fenómeno arraigado no sólo en la época de la Restauración, sino en todo el período considerado ${ }^{48}$.

Para comprender, en el caso que nos ocupa, la forma y la eficacia de esta presión, es esencial darse cuenta de la experiencia que transmitió el Banco de España a los responsables de la CAT. En efecto, al menos desde su conversión en emisor único de dinero legal en 1874, esta entidad había acumulado una notable práctica negociadora con los responsables de la Hacienda en todo lo relacionado con el desarrollo de las operaciones financieras del Banco con el Tesoro y con la aplicación de los contenidos del decreto fundacional de dicho año. Dado que la gestión arrendada del

${ }^{43}$ Resulta de gran utilidad al respecto releer el texto de Diego Mateo del Peral (1974a), pp. 78 y 104-105, para darse cuenta de la prolongación que tenían los intereses de los políticos más encumbrados de la Restauración más allá de la escena política. 
monopolio de tabacos exigía asimismo una permanente relación con la Hacienda, el Banco de España trasladó a la dirección de la CAT su experiencia negociadora, que fue importante siempre pero sobre todo en las renovaciones de los contratos de arriendo.

Todo apunta a que ambas partes se sintieron relativamente cómodas en un modelo de relación cotidiana - no exenta de problemas-, que se prolongó más allá del período de vida de la CAT, en el que la negociación y la transacción fueron el procedimiento habitualmente usado para solventar los conflictos y el móvil que guió su conducta, pues las dos asumieron las obligaciones que se derivaban del vínculo contractual que las unía. En alguna ocasión, incluso, el derecho a la negociación entre las partes (Ministerio y empresa) se antepuso al del Parlamento a enmendar y modificar lo pactado previamente por ellas ${ }^{49}$. En los demás casos, salvo en el contrato de 1945, lo habitual fue que los máximos responsables de la Compañía negociasen con el ministro de Hacienda, tanto antes como durante el trámite en el cuerpo legislativo correspondiente, las directrices esenciales de las leyes que habían de regular cada nuevo contrato, para después redactar el contenido del mismo - y del reglamento correspondiente - una comisión mixta con representación de ambas partes. Esta tarea supuso no pocas veces una suavización en la práctica de las cláusulas más perniciosas para los intereses del arrendatario. Además, uno de los principales resultados conseguidos por éste con la explotación al máximo de esta vía negociadora fue que nunca, salvo en 1945, la Hacienda procedió a realizar un nuevo concurso de arrendamiento al concluir los contratos, consiguiendo así eludir la disputa de los beneficios de monopolio por parte de otras empresas interesadas en el negocio.

Los primeros años del arriendo son un buen ejemplo de cómo las necesidades de la Hacienda y la fluidez de las relaciones de los responsables de la CAT con el partido gobernante fueron aprovechadas por éstos para obtener contrapartidas importantes en la negociación. En 1892 consiguieron que se modificase a su favor el canon de arriendo del contrato de 1887 a cambio de hacerse cargo de la gestión del impuesto del timbre y del giro mutuo del Tesoro. En 1896, antes de que finalizase la vigencia del primer contrato, las urgentes necesidades de recursos extraordinarios para financiar la guerra antillana llevaron al Gobierno de Cánovas a con-

19 Esto ocurrió en 1896 cuando el contenido completo de un nuevo contrato de arrendamiento fue pactado por el ministro de Hacienda y el presidente de la CAT y después debatido sin posibilidad de ser modificado en el Parlamento ante las protestas de las minorías políticas. 
ceder la prórroga del contrato por 25 años - más del doble del tiempo establecido en el primero-, además de otras ventajas, a cambio de asegurarse un nuevo anticipo y un mayor control de la gestión del monopolio al unir en una sola persona al representante del Estado y al presidente de la CAT.

Sin embargo, tan sólo cuatro años después, en 1900, las reformas presupuestarias de Fernández Villaverde sirvieron para que se hiciese un contrato nuevo, respetando el período de vigencia del anterior, y para que la Hacienda, que aumentó su poder de negociación, recuperase buena parte del terreno perdido hasta entonces, sobre todo en lo tocante a las comisiones a percibir por la CAT. Algo semejante ocurrió en 1909, cuando el Gobierno conservador de Maura trató de elevar el rendimiento del monopolio para la Hacienda recortando otro poco estas comisiones y reduciendo el interés al capital empleado, que se venía abonando a la CAT. No obstante, ésta consiguió arrancar en contrapartida el compromiso del Gobierno de no obligarla a ulteriores novaciones antes de que finalizase el contrato en vigor.

Nuevos y mayores apuros pasó la CAT durante los años de la Primera Guerra Mundial, tanto por los renovados intentos de los gobiernos de la época de seguir recortando sus comisiones y privilegios (exención de impuestos, abono del interés al capital empleado), como por la conjunción de los negativos efectos derivados de la contienda bélica y de una gestión deficiente (aumento de los costes, mala calidad de las labores, desabastecimiento, expansión del contrabando). Aun así, la CAT consiguió en 1921 que se prorrogase el arrendamiento por 20 años más, haciendo uso de su gran capacidad de negociación e influencia política. Téngase en cuenta que el contrato de 1921 se aprobó con un Gobierno presidido por el conservador-maurista Manuel Allendesalazar, que había sido gerente de la CAT entre 1913 y 1919 (Cuadro 2).

La prueba de fuego para el modelo de negociación practicado por el Estado y la CAT durante más de medio siglo fue la Ley de Bases de 1944 y el contrato de 1945. Los responsables de la Hacienda del nuevo Estado, imbuidos de principios estatificadores en alza en la época y de un firme rechazo de las prácticas políticas de los gobiernos «demoliberales» anteriores a la Guerra Civil, sacaron adelante un proyecto de concesión del monopolio semejante al empleado por Calvo Sotelo con el petróleo en 1927. Los dirigentes de la CAT, contrarios a la incorporación del Estado al capital y a la gestión de la empresa y reacios a tener que pasar por un nuevo concurso de adjudicación y a crear otra empresa distinta para 
su gestión, se mostraron inicialmente opuestos a los propósitos gubernamentales, pero finalmente hicieron gala otra vez de un gran pragmatismo y prefirieron continuar con la gestión del monopolio a cambio de aceptar estas imposiciones del Estado. De todas formas, no faltó la negociación, si bien la posición de los responsables de la CAT en ella fue débil, como nunca lo había sido hasta entonces. Aun así, consiguieron reintroducir en el momento de la adjudicación algunas cuestiones «técnicas» que les beneficiaban y, sobre todo, conservaron la dirección de la nueva empresa (Tabacalera) a pesar de que su principal accionista era el Estado.

Finalmente, adaptados a la nueva realidad de una empresa sujeta al derecho privado (Ley de Sociedades Anónimas de 1951) pero de capital mixto y fuerte control del delegado del Gobierno, los representantes del capital privado desplegaron otra vez en 1971 toda su capacidad de influencia y negociación para conservar su posición en Tabacalera y evitar tanto la desaparición del monopolio, como defendían los partidarios de seguir con el proceso de liberalización de la economía iniciado con el Plan de Estabilización de 1959, como el paso definitivo hacia su completa estatificación, como proponían otros apoyándose en la doctrina jurídica, en la existencia del INI o en la experiencia de monopolios como el francés ${ }^{50}$. El resultado es que consiguieron mantenerse en la gestión del monopolio y seguir participando de sus beneficios, si bien cediendo la dirección de Tabacalera al Estado en tanto que accionista ahora dominante. Una vez más, el Gobierno, a pesar de las mayores capacidades de la Administración pública con respecto a la de un siglo atrás, se había inclinado por la solución pragmática de la continuidad del monopolio - y de su gestión arrendadacomo la fórmula más eficaz para la exacción del impuesto y la apropiación de los beneficios extraordinarios incorporados a él ${ }^{51}$. Y para ello disponía

"Véase Martin-Retortillo y Salas (1969), pp. 127-155. Los argumentos de los responsables de Tabacalera pueden verse en un folleto editado por ella, aunque sin autoría expresa - Maureta (1975), p. 758, dice que fue escrito por un «autorizado Profesor»-, titulado «Análisis de los distintos medios posibles de gestión de la actividad económica del Estado en relación con el tabaco y servicios anejos». Para el consejo de Tabacalera, la mejor opción era la prórroga del contrato vigente, gracia a la que se consideraba con derecho, entre otras razones, por su dilatada hoja de servicios al Estado, por su capacidad demostrada para gestionar un complejo proceso industrial y comercial, así como por su «perfecta compenetración» con los delegados del Gobierno y su «disciplinada subordinación» al Ministerio de Hacienda. Ninguno de estos argumentos era nuevo. Con más o menos matices habían sido expuestos en todas las renovaciones de los contratos anteriores.

${ }^{51}$ El propio Gobierno decía en 1969 en las Cortes lo siguiente: «La desaparición del Monopolio llevaría consigo consecuencias de indole fiscal muy perjudiciales para nuestra Hacienda. Sería preciso reorganizar todo un sistema de imposición, que tiene su base en 
de una empresa con dilatada experiencia en la materia, que ahora se convertía definitivamente en pública por razón de la posición dominante del capital de este origen y por su control de la dirección de la misma.

\section{CONCLUSIONES}

En este trabajo se ha intentado aportar la evidencia necesaria para poder definir el tipo de empresas que fueron la CAT y Tabacalera desde el punto de vista de la regulación a la que estuvieron sometidas por el Estado, de la estructura de su propiedad y del control de su gestión. A partir de estos tres elementos, y teniendo en cuenta algunas de las implicaciones de las teorias de la agencia y de la regulación positiva, se ha abordado una explicación selectiva de la dilatada permanencia de la gestión arrendadada $\multimap$ concedida - del monopolio de tabacos a estas dos empresas.

Partiendo de que las crónicas necesidades financieras de la Hacienda de la Restauración, a falta de una reforma tributaria que las satisfaciese cumplidamente, condujeron al Gobierno liberal de Sagasta a ceder en 1887 la gestión del monopolio de tabacos a un contratista particular (la CAT), hemos sostenido que ésta afianzó su posición como arrendataria aprovechando las posibilidades de negociación que le daba su relación contractual con el Estado, la experiencia en estas lides de su principal accionista, el Banco de España, y la debilidad negociadora de los gobiernos de esta primera época del arriendo. Todo esto cobra más sentido si se tiene en cuenta que el garante final de la gestión del arrendamiento del monopolio era el propio banco emisor y que su interés en conservarla se justifica por la necesidad de fortalecer su función de banco del Estado, de cuyo cumplimiento salían mutuamente beneficiados la Hacienda y el Banco.

Este modelo de relación contractual entre la Hacienda y la CAT contó además, en aras de su estabilidad, con dos firmes apoyos. Por un lado, el control de la gestión de esta empresa por parte del Banco de España, en colaboración con el Urquijo, permitió asegurar en grado elevado el

el Monopolio, y que se caracteriza por su economía en la administración, su extraordinaria agilidad y eficacia, su imposibilidad de fraude fiscal y su elevado rendimiento. A estos efectos, los ingresos líquidos en el Tesoro en el año 1968, han ascendido a 12.566 millones de pesetas. La entidad de esta cifra da ićea de lo difícil que sería sustituir esta recaudación por ingresos tributarios de exacción normal». Citado en Martín-Retortillo y Salas (1969), p. 17 , nota 15 . 
cumplimiento de las obligaciones contractuales del arrendatario en beneficio de la Hacienda ${ }^{52}$. Por otro, la táctica de situar al frente del consejo y de la dirección de la CAT a políticos o a personajes con experiencia en la gestión hacendística o muy relacionados con los partidos gobernantes favoreció la fluidez de sus relaciones con la Hacienda, que no estuvieron por ello exentas de tiranteces y conflictos. Ambos apoyos, además, reforzaron el poder negociador de la empresa, esto es, su capacidad para persuadir a los responsables del Ministerio de regular la gestión del monopolio contando con los intereses del arrendatario.

Desde principios de siglo, la estrategia de la CAT se hizo más conservadora ante los avances del Estado, que recuperó poder de negociación e hizo valer cada vez más su condición de propietario del monopolio. Aumentó poco a poco su control sobre la gestión del arrendatario y recortó gradualmente parte de las ganancias monopolistas que le correspondían a éste. En esta trayectoria el punto crítico está en los años 1944-45 cuando el Estado, en el momento de mayor influencia de los vientos estatificadores, no llegó a dar este paso - recuperación de la administración directa del monopolio o bien gestión del mismo por medio de una empresa públicay se quedó a mitad de camino en relación a la situación anterior. Es decir, entre la mera continuidad y la completa estatificación se quedó en el punto intermedio que representaba el modelo de concesión del monopolio de petróleos ensayado por Calvo Sotelo en 1927 con la CAMPSA, reconociendo con ello implícitamente que ni la experiencia de la CAT durante más de medio siglo había sido negativa para la Hacienda ni el modelo francés del SEITA, que era una referencia a tener en cuenta, se consideraba apropiado al caso español.

A partir de entonces la colaboración del Estado con el capital privado en la gestión del servicio público patrimonializado y su destacada participación en el capital de Tabacalera no fueron razones suficientes como para impedir que la dirección de esta empresa continuase en manos del capital privado, que sólo pasó a ocupar una posición secundaria en ella tras convertirse el Estado en el accionista dominante después del contrato de 1971.

La teoría de la regulación positiva nos ha proporcionado un término, el de «captura» o «apropiación» del regulador (Estado) por el regulado

52 Es ilustrativo al respecto que el Banco de España se opusiese a que la CAT emprendiese otras actividades y negocios ajenos a la gestión del monopolio, alternativa que fue defendida por algunos miembros de su consejo particularmente en la primera década del siglo. 
(agente privado) para expresar la colusión de estrategias entre ambos en provecho de éste. Stigler (1971) señala que, por lo general, la regulación es «conseguida» básicamente por el agente privado y diseñada y aplicada para su beneficio. En el caso que nos ocupa, sin negar las ventajas que ha reportado a la Hacienda el arriendo del monopolio de tabacos, parece cierto que desde el momento en que el Banco de España se interesó por este negocio y fundó la CAT, ésta consiguió uno de los principales objetivos de la estrategia de cualquier empresa regulada: controlar la entrada de posibles competidores en su industria. En ningún momento, excepción hecha del concurso realizado al amparo de la Ley de Bases de 1944, la regulación del monopolio de tabacos puso en peligro su condición de arrendatario y el derecho que le asistía como tal a seguir detrayendo una parte de los beneficios monopolísticos correspondientes; pero ni en este caso logró ser desalojado de su privilegiada posición. Más aún, ni siquiera la acentuación de los rasgos de empresa pública de Tabacalera, es decir, la asunción plena por parte del Estado, como accionista dominante, del control de la gestión de esta empresa a partir del contrato de 1971 ha supuesto la exclusión del capital privado de esta gestión, en la que se ha mantenido en una posición secundaria percibiendo la parte correspondiente de los beneficios del monopolio. Esta situación ha durado hasta la privatización de 1998 , en la que el capital privado ha recuperado el terreno perdido desde 1945 en el seno de Tabacalera, al tiempo que desaparecía el monopolio en el marco de las directrices de la construcción del mercado único europeo.

\section{BIBLIOGRAFÍA}

AlBiNana, César (1987): «El arrendamiento del monopolio del tabaco en España: notas históricas», Hacienda Pública Española, núm. 108-109, pp. 377-392.

Alonso, Luis (1996): «Estrategias empresariales de los monopolios españoles: de la gestión pública a la gestión privada en el estanco del tabaco 1887-1936», en Comín, F., y MARTín ACEÑa, P. (eds.): La empresa en la historia de España, Madrid, Civitas, pp. 383-398.

Comin, Francisco (1991): «Los monopolios fiscales», en Comín, F., y MARTín ACENA, P. (dirs.): Historia de la empresa pública en España, Madrid, Espasa Calpe, pp. 139-175.

- (1995): La empresa pública en la España contemporánea: formas históricas de organización y gestión (1770-1995), Madrid, Fundación Empresa Pública, Programa de Historia Económica, DT 9505.

- (1996): Historia de la Hacienda pública, II. España (1808-1995), Barcelona, Critica. 
Comin, Francisco, y Martin Acena, Pablo (1998): El negocio del tabaco en la bistoria, Madrid, Fundación Empresa Pública, Programa de Historia Económica, DT 9801.

- (1999): Tabacalera y el estanco del tabaco en España, 1636-1998, Madrid, Fundación Tabacalera.

Comfañia ArRendataria de Tabacos (1887): Ley y Real Decreto sobre el arriendo de la Renta. Escritura de constitución y estatutos de la Compañia, Madrid, Est. Tipográfico «Sucesores de Rivadeneyra».

Delgado, Eleuterio (1892): La renta de tabacos, Madrid, Tipografía de Miguel Ginés Hernández.

FAMA, Eugene (1984): «Problemas de agencia y teoría de la empresa», Información Comercial Española, núm. 611 (julio), pp. 53-65.

FAMA, E., y JENSEN, M. (1983): «Separation of Ownership and Control», Journal of Law and Economics, vol. 26 (junio), pp. 301-325.

FERNÁNDEZ, Zulima (1994): «Comportamiento y eficiencia de la empresa pública», en Velarde, J.; Garcia Delgado, J. L., y Pedreño, A.: El Estado en la economía española, Madrid, Civitas, pp. 105-124.

Galve, Carmen, y Salas, Vicente (1997): «Propiedad y control en la empresa española», Economistas, núm. 73, pp. 70-77.

García RuIz, José Luis, y TorTella, Gabriel (1994): «Trayectorias divergentes, paralelas y convergentes: la historia del Banco Hispano Americano y del Banco Central, 1901-1965», en Hernández Andreu, J., y García Ruiz, J. L. (comps.): Lecturas de Historia Empresarial, Madrid, Civitas, pp. 401-427.

GonzÁlez, Antonio; SÁnchez, Domingo, y Torres, Eugenio (1981): La Banca y el Estado en la España contemporánea (1939-1979), Madrid, Ed. Gráficas Espejo.

Jensen, M., y MeckLING, W. (1976): «Theory of Firm: Managerial Behavior, Agency Costs and Ownership Structure», Joumal of Financial Economics, vol. 3, núm. 4, pp. 305-360.

Martin Aceña, Pablo (1997): «El Banco de España. Una visión histótica», Papeles de Economía Española, núm. 73, pp. 4-14.

Martin-Retortillo, Sebastián, y Salas, Javier (1969): El monopolio de tabacos. Aspectos juridicos de su explotación y organización, Madrid, Tecnos.

Mateo Del Peral, Diego (1974a): «Aproximación a un estudio sociológico de las autoridades económicas en España (1868-1915)», en TorTella, G. (dir.), La Banca española en la Restauración. Tomo I: Política y finanzas, Madrid, Servicio de Estudios del Banco de España, pp. 15-106.

- (1974b): «Autoridades económicas. Presidentes del Consejo de Ministros, Ministros de Hacienda, de Fomento y Gobernadores del Banco de España de 1868 a 1915», en Tortella, G. (dir.), La Banca española en la Restauración. Tomo II: Datos para una bistoria económica, Madrid, Servicio de Estudios del Banco de España, pp. 75-97.

MAureTA, José M. ${ }^{a}$ (1975): El tabaco en el monopolio español y en la economía mundial, Madrid, Facultad de C. Económicas, Universidad Complutense.

MuÑoz, Juan (1969): El poder de la banca en España, Algorta (Vizcaya), Ed. Zero. Peltzman, Sam (1993): «George Stigler's Contribution to Economic Analysis of Regulation», Journal of Political Economics, vol. 101, pp. 818-832. 
Posner, Richard (1974): «Theories of Economic Regulation», Bell Journal of Economics and Management Science, vol. 5, núm. 2, pp. 335-358.

STIGLLR, George (1971): «The Theory of Economic Regulation», Bell Journal of Economics and Management Science, vol. 2, núm. 1, pp. 1-21.

Tamames, Ramón (1972): «El monopolio de tabacos», Hacienda Pública Española, núm. 18 , pp. 15-44.

Tedie, Pedro, y Marichal, Carlos (Coords.), (1994): La formación de los bancos centrales en España y América Latina (Siglos XIX y XX). Vol. I: España y México, Madrid, Banco de España, Estudios de Historia Económica, núm. 29.

Tejerizo, José Manuel (1975): Los monopolios fiscales, Madrid, Instituto de Estudios Fiscales.

Toledano, E. (1860): Curso de instituciones de la Hacienda pública de España, Madrid, dos tomos.

Torres, Eugenio (1998): La fundación de la Compañia Arrendataria de Tabacos, Madrid, Fundación Empresa Pública, Programa de Historia Económica, DT 9808.

TORTElla, Gabriel (1970): «El Banco de España entre 1829 y 1929. La formación de un banco central», en Ruiz Martín, F., y otros: El Banco de España. Una bistoria económica, Madrid, Banco de España.

Tortella, Gabriel (1987): «La implantación del monopolio de los explosivos en España», Hacienda Pública Española, núm. 108/109, pp. 393-410.

- (1994): «El monopolio de petróleos y Campsa, 1927-1947», en Hernández Andreu J., y Garcin Ruiz, J. L. (comps.): Lecturas de Historia Empresarial, Madrid, Civitas, pp. 265-302. 